\title{
Estudio de público de museos: el aporte teórico-metodológico de la semiótica
}

María Marta Reca*

RECA, M.M. Estudio de público de museos: el aporte teórico-metodológico de la semiótica. R. Museu Arq. Etn., São Paulo, n. 21, p. 369-381, 2011.

Resumo: Nos últimos anos a necessidade de conhecer com maoir profundidade a experiência da visita e indagar sobre a forma em que os visitantes interpretam a proposta expositiva tornaram-se relevantes. A semiótica nos proporciona um conjunto de instrumentos teórico/empíricos para a aplicação de um método preciso que nos permita dar conta do processo de produção, comunicação e transformação do significado. De um ponto de vista construtivista e cognitivo, aplicando a análise de discurso pretende-se avaliar a eficácia comunicativa de uma sala de exposição do Museu de La Plata (UNLP). Busca-se construir um modelo estabelecendo relações entre o contexto de representação, a sala de exposição, e o contexto de apropriação, os discursos produzidos pelos visitantes no momento da visita.

Palavras-chave: Semiótica simbólica - Aproximação qualitativa - Comunicação - Museus - Estudos de público.

\section{Introducción}

E $\mathrm{n}$ los últimos años uno de los ejes de

Cinnovación de los museos ha sido el desarrollo de nuevas estrategias expositivas y la incorporación de elementos interactivos en las salas de exhibición. Sin embargo, el cambio más profundo reside en el desplazamiento del centro de atención desde el objeto hacia el visitante, para analizar, desde distintos puntos de vista, la manera en que éstos se conectan con la exhibición, tanto en sus aspectos cognitivos y comportamentales, como emocionales.

$\left.{ }^{*}\right)$ Facultad de Ciencias Naturales y Museo. UNLP. <mariamartareca@hotmail.com>
Este interés creciente por conocer al destinatario de las exhibiciones esta asociado, entre otras razones, con las nuevas miradas sobre el concepto de patrimonio cultural y las reflexiones en torno a su función educativa, buscando generar en el museo un espacio de aprendizaje significativo. La evaluación y análisis de las formas en que los visitantes perciben, recepcionan y elaboran los mensajes propuestos en una exhibición, constituye una instancia fundamental tanto para la reformulación y ajustes de las mismas como para el desarrollo de una política institucional que aspire a cumplir su misión educativa.

El objetivo de este trabajo es el de poner en relieve el aporte teórico de la semiótica, en particular la semiótica simbólica, en el análisis de público. Asimismo exponer los procedimientos 
metodológicos que fortalecen el uso de metodologías cualitativas en este campo. El mismo será ejemplificado por su aplicación en un estudio de visitantes realizado a partir de la recepción del público de la sala de exhibición permanente de etnografía "Espejos Culturales", del Museo de La Plata. ${ }^{1}$

Según Zunzunegui (2003), el museo propone al visitante una triple actividad: pragmática, cognitiva y estética. La actividad pragmática es identificable en la visita a partir de los desplazamientos de los visitantes y estructurada en una serie de acciones físicas más o menos reguladas. La actividad cognitiva se refiere a la acción de adquirir un determinado saber garantizado por el museo y en el que se manifiestan los valores profundos de una cultura. En este sentido puede hablarse del museo como espacio cognitivo en el que tiene lugar la búsqueda del sujeto que procura la conjunción con el objeto de valor. En cuanto a la actividad estética, ésta se despliega en la medida en que el visitante puede llegar a una esthesis en su relación con la propuesta museográfica.

A su vez, la visita a un museo involucra tres contextos: personal, social y físico. El contexto personal incluye los intereses, motivaciones e inquietudes de los visitantes, que pueden influir de una manera decisiva en los resultados de la visita. El contexto social implica a las personas con las que realiza la visita, los contactos con otros visitantes y con el personal del propio museo, que juegan un papel relevante en la experiencia museística. El contexto físico engloba tanto los aspectos arquitectónicos, como los objetos y artefactos que contiene el museo y que ejercen una poderosa influencia. (Pérez Santos 2000)

Las complejas interacciones entre estos ámbitos dan como resultado una construcción única por parte del visitante, "creando" la experiencia de la visita. De esta forma, la atención

(1) Esta sala de exhibición fue inaugurada en marzo de 2006 Museo de La Plata, Facultad de Ciencias Naturales y Museo de la Universidad Nacional de La Plata. Una descripción de la sala de exhibición fue presentada en oportunidad de las V Jornadas de Etnografía y Métodos Cualitativos (agosto de 2007). prestada a una exposición está filtrada por el contexto personal, mediatizada por el contexto social e inmersa en el contexto físico. Aunque cada uno de estos contextos puede considerarse de forma separada, funcionan en la realidad como un todo integrado.

En tal sentido, podemos afirmar que cada visitante se conecta de modo diferencial con la exhibición, su percepción es selectiva, de modo que en él recae mucho más la producción de nuevas síntesis cognoscitivas que la adquisición de información acabada. Para esto es necesario dar mayor espacio al protagonismo, la interacción y el espíritu crítico.

A partir de la sala de exhibición antes mencionada, procuramos poner en relación dos dominios de análisis, que presentan particularidades, articulaciones y elementos propios. Ambos son analizados desde una perspectiva semiótica, concebidos en su textualidad y en su dimensión comunicativa. El primero, la sala propiamente dicha, se refiere a la "puesta en escena” de los materiales etnográficos, la conexión (configuración) real y perceptible de un espacio bien delimitado en cuyo interior se articulan objetos, ideas, imágenes, secuencias en las que está anclado el conocimiento de "los otros".

El segundo refiere al análisis de los "sujetos observadores", "perceptores" e "interpretantes", cuya configuración se materializa en el discurso producido por los visitantes luego de la visita a la exhibición. La tarea consiste en la problematización de ambos dominios como contextos de significación y sus relaciones de modo de evaluar la eficacia comunicativa de la visita.

\section{La mirada semiótica y los contextos de significación}

Los objetos de colección, se trate de objetos de arte, arqueológicos, etnográficos o de otro tipo adquieren diversos sentidos según el sistema de referencia del que forman parte. A decir verdad, este postulado impregna cualquier experiencia humana, nuestra facultad semiótica consiste, justamente en esta posibilidad/condición de adjudicación de sentido al mundo que nos rodea, incluyéndonos a nosotros mismos. 
Por definición, ninguna experiencia humana queda fuera del mundo de la significación o, mejor dicho, para esta operación siempre será necesaria la presencia de un sujeto-

Pero los significados no están en la esencia de las cosas, no constituyen una condición material o espiritual que forma parte de la naturaleza inmanente de las cosas, sino que son el resultado de procesos cognitivos por los cuales percibimos, ordenamos, categorizamos, representamos e interpretamos el mundo.

Siguiendo a Magariños de Morentín, el planteo semiótico fundamental consiste, en que “... los fenómenos que constituyen el mundo no se nos dan desde sí mismos, sino que nosotros los identificamos adecuándolos a nuestras posibilidades de designación; ni contienen en sí mismos su razón de ser, sino que la proyectamos nosotros en función de las categorías disponibles en nuestra estructura conceptual; ni tampoco son vistos (ni comprendidos) tal como son, sino como nuestra modalidad de enunciación nos hace verlos (o comprenderlos) en el entorno perceptual correspondiente" (Magariños de Morentín 2008:66) La explicación de la significación tendrá que partir del modo en que el ser humano expresa cómo ese fenómeno ha entrado en su mundo de experiencia. Lo expresa enunciándolo y entra en su mundo interpretando los enunciados (pan-semióticos) de su aprendizaje. El enunciado que él produce y los enunciados aprendidos constituye el corpus necesario para fundamentar cualquier investigación que pretenda explicar el significado atribuido a los fenómenos de su entorno. (Magariños de Morentín 2008)

Cuando los objetos pasan a formar parte de las colecciones de un museo, salen del circuito utilitario para ingresar en nuevos ámbitos semióticos. Como expresa Pomian (1990) todo objeto visible encuentra un valor que reside en su capacidad de servir a la producción de algún sentido diferente de aquel por el cual ha sido construido o consumido. Es decir que, el conjunto de significaciones de las que será embestido un objeto de colección depende de la entramada red de relaciones semióticas (icónicas, simbólicas e indiciales) establecidas en algún contexto particular, para cierto intérprete en el marco de una comunidad dada.

Desde aquí es posible asumir un concepto dinámico de patrimonio. Los valores adjudicados a un bien patrimonial son recreados por diferentes intérpretes (en instancias individuales y colectivas). "El patrimonio surge cuando una comunidad cultural le da forma a esos lazos de conectividad y pertenencia, otorgándole calidad de representación a los bienes tangibles e intangibles que elige valorar. Hace visibles esos lazos creando constantemente significados que se plasman en danzas, cantos, esculturas o arquitecturas y tantas otras formas creativas. Hay que reconocer, por tanto, que el patrimonio se halla en constante redefinición y movimiento. Dicho de otra manera, lo que mantiene en vida el patrimonio es que los individuos de la comunidad cultural recuerden y recreen su significado en cada período histórico." (Arizpe y Nalda 2002:210)

Restringiéndonos a las colecciones etnográficas, hemos identificado al menos tres contextos de significación a partir de los cuales los objetos etnográficos adoptan sentido para determinados intérpretes. A su vez, esa interpretación se materializa/expresa por medio de las formas de semiosis sustituyentes icónicas, indiciales y simbólicas, otorgando al objeto de colección su valor de signo.

El criterio de delimitación de cada uno de los contextos se relaciona con tres dominios de conocimiento: el de las colecciones etnográficas, el de la exhibición de dichas colecciones y el de la interpretación por parte de los visitantes. Denominaremos a cada uno de estos dominios como el contexto de recolección, el contexto de re-presentación y el contexto de apropiación respectivamente.

En cada uno de ellos es necesario identificar los referentes, los intérpretes y las relaciones de producción de sentido. En este trabajo nos ocuparemos particularmente del último contexto, el de apropiación.

Desde un punto de vista constructivista, algunos principios de la semiótica y la teoría de la comunicación estarán referenciados en la experiencia del observador-visitante. Éstos pueden ser enunciados como: 
- El acto de adjudicación de sentido es siempre una interpretación.

- El fenómeno no preexiste al discurso.

- Existe un único nivel de representación mental (hipótesis inter-semiótica).

- La referencialidad es una condición del proceso de interpretación.

- El acto de adjudicación de sentido se encuentra circunstancialmente situado.

- Significación es el conjunto de todos los sentidos vigentes en determinada comunidad a determinado fenómeno (su dispersión).

- Todas las interpretaciones explícitas que recibe el fenómeno en estudio, es a lo que también puede denominarse el mundo semiótico posible construido acerca de tal fenómeno.

Si bien, con un criterio analítico, es posible distinguir las distintas semióticas intervinientes en la producción de sentido, existe un único nivel de representación mental, la estructura conceptual, en la cual la información lingüística, sensorial y motriz es compatible.
Este enunciado teórico es lo que Magariños de Morentín, citando a Jackendorf, denomina Hipótesis intersemiótica: "Existe un único nivel de representación mental, la estructura conceptual inter-semiótica, en el cual las representaciones icónica, indicial y/o simbólica, de la información lingüística, sensorial y motriz son compatibles, lo que permite la producción de la interpretación” (Magariños de Morentín 2008:58)

A partir de la concepción triádica del signo de Peirce, intentamos expresar en el cuadro 1 los contextos de significación y las relaciones intercontextuales. La noción peirceana del signo permite hacer explícita la estructura lógica desde la cual se definen los diferentes niveles semánticos en los cuales el objeto de colección se vincula con alguna otra cosa, a la cual, representa, según los contextos de quien lo produce, lo exhibe y lo observa.

\section{Habitus y cognición}

Desde la perspectiva constructivista, las personas procesan nuevos conocimientos sobre las estructuras cognoscitivas ya existentes que dan

\section{Cuadro 1}

Permite visualizar las relaciones inter-contextuales y establecer el carácter mediador de la sala de exhibición y su condición de re-presentación

\begin{tabular}{|c|c|c|c|}
\hline & $\begin{array}{l}\text { EN ALGUNA } \\
\text { RELACIÓN }\end{array}$ & POR ALGO & $\begin{array}{c}\text { PARA } \\
\text { ALGUIEN }\end{array}$ \\
\hline $\begin{array}{l}\text { CONTEXTO DE } \\
\text { RECOLECCIÓN }\end{array}$ & $\begin{array}{l}\text { Contexto analítico- } \\
\text {-descriptivo, funcional } \\
\text { y simbólico del objeto } \\
\text { etnográfico }\end{array}$ & $\begin{array}{l}\text { Cualidades formales } \\
\text { del objeto, documentos, } \\
\text { fotos, otros. }\end{array}$ & $\begin{array}{l}\text { Interpretación a } \\
\text { partir de la relación } \\
\text { nativo-antropólogo }\end{array}$ \\
\hline $\begin{array}{c}\text { CONTEXTO DE } \\
\text { RE-PRESENTACIÓN }\end{array}$ & $\begin{array}{l}\text { Contexto discursivo } \\
\text { disciplinar }\end{array}$ & $\begin{array}{l}\text { La pertenencia a un } \\
\text { contexto de recolección } \\
\text { específico }\end{array}$ & $\begin{array}{l}\text { El curador } \\
\text { (sujeto colectivo) }\end{array}$ \\
\hline $\begin{array}{l}\text { CONTEXTO DE } \\
\text { APROPIACIÓN }\end{array}$ & $\begin{array}{l}\text { La disposición espacial y } \\
\text { contextual en la sala de } \\
\text { exhibición }\end{array}$ & $\begin{array}{l}\text { Discurso enunciado a } \\
\text { partir de la experiencia } \\
\text { de la visita }\end{array}$ & El visitante \\
\hline
\end{tabular}


sentido a los mismos. Los visitantes que acuden a una exposición movilizan esquemas cognitivos previos con los cuales se pueda acoplar/conectar/asociar la nueva información. Cada visitante realiza una síntesis subjetiva frente a la propuesta del museo, selecciona una de las múltiples estrategias posibles de recorrido, evoca de lo ya visto, de lo ya escuchado, una secuencia de signos de acuerdo a "una disposición de su mente" y a partir de ello, se identifica, considera ajeno, se sorprende, ignora o rechaza aquello que ha seleccionado como campo de significación del despliegue expositivo.

Las formas de apropiación cognitiva del patrimonio exhibido se instala en el espacio de una experiencia situada que, condicionada por las restricciones materiales de la sala de exhibición, es "actualizada” por cada visitante/ intérprete según un sistema de relaciones que involucra su capital cultural y se "hace observable" a través de su producción discursiva. Según Bourdieu, el habitus, producto y lugar de la historia individual y colectiva asegura la presencia activa de las experiencias pasadas que, depositadas en cada organismo bajo la forma de esquemas de percepción, de pensamiento y de acción, tiende, más seguramente que todas las reglas formales y todas las normas explícitas, a garantizar la conformidad de las tácticas y su constancia a través del tiempo. (Bourdieu 1996)

La noción de habitus definida por Bourideu permite asumir las estructuras cognitivas de los individuos como estructuras sociales incorporadas. El habitus es una capacidad adquirida y naturalizada que contiene la historia individual y los contextos de las prácticas sociales. Así, la génesis del discurso está enraizada en el capital cultural. Este es el conjunto de saberes y disposiciones adquiridas socialmente que permiten producir y reproducir las estrategias de acción y apropiación. El capital cultural no puede ser acumulado más allá de las capacidades de apropiación de un agente singular y muere con las capacidades biológicas de su portador. ${ }^{2}$

(2) En relación a los museos Bourdieu analizó la apropiación del arte como elemento distintivo de clase.
Desde el punto de vista epistemológico, y asumiendo sus connotaciones para nuestro campo de análisis, el concepto de habitus (y su marco relacional con el concepto de capital cultural) permite, instalar la investigación en un punto de encuentro entre las posturas objetivistas y subjetivistas, dado que la génesis del significado tiene carácter relacional. ${ }^{3}$

... "las representaciones de lo agentes varían según su posición (y los intereses asociados) y según su habitus (...) El habitus es a la vez un sistema de esquemas de producción de prácticas, un sistema de esquemas de percepción y de apreciación de las prácticas. $\mathrm{Y}$, en los dos casos, sus operaciones expresan la posición social en la cual se ha construido. En consecuencia, el habitus produce prácticas y representaciones que están disponibles para la clasificación, que están objetivamente diferenciadas; pero no son inmediatamente percibidas como tales más que por los agentes que poseen el código, los esquemas clasificatorios necesarios para comprender su sentido social." (Bourdieu 1996:134)

Estos esquemas de acción y producción de prácticas y representaciones son el sustrato en el que se asienta la construcción de sentido. Según Ausubel et al. (1983) un aprendizaje es significativo cuando los contenidos son relacionados de modo no arbitrario y sustancial en lo que al alumno (visitante) ya sabe. Por relación no arbitraria y sustancial se debe entender que las ideas se relacionan con algún aspecto existente específicamente relevante de la estructura cognoscitiva del individuo como una imagen, un símbolo

(3) "De modo muy general, la ciencia social, en antropología como en sociología o en historia, oscila entre dos puntos de vista aparentemente incompatibles: el objetivismo y el subjetivismo, o, si se prefiere, el fisicalismo y el psicologismo (que puede tomar distintos matices, fenomenológico, semiológico, etcétera). Por un lado puede "tratar los hechos sociales como cosas", según la vieja máxima durkheimiana, y dejar así de lado todo lo que deben al hecho de que son objetos de conocimiento -o de desconocimiento- en la existencia social. Por otro lado, puede reducir el mundo social a las representaciones que de él se hacen los agentes, consistiendo entonces la tarea de la ciencia social en producir un "informe de los informes" producidos por los sujetos sociales.” (Bourdieu 1996:128) 
o un concepto. ${ }^{4}$ Una de las estrategias de aprendizaje que apuntan a la realización de asociaciones significativas es aquella que se dirige, por analogía, comparación, contraste u oposición al conocimiento que el individuo tiene como resultado de la percepción/recepción/comprensión de su mundo cotidiano. En la experiencia de la visita al museo, no se trata necesariamente de asociaciones "correctas" en el sentido instructivo del término, sino de experimentar situaciones reflexivas que minimicen la distancia entre la propuesta expositiva y el mundo del visitante. De allí que la exposición generalmente está tan cargada de azar e incertidumbre como de certezas y confirmaciones. De allí que se constituya en un espacio abierto, dinámico, que admite variadas lecturas. (Cury 2005)

En la misma línea de pensamiento se encuentran los trabajos de M. Asensio para quien desde la perspectiva psicológica más moderna, el aprendizaje se considera un proceso situado, contextual y pragmático, ligado a dominios y ámbitos específicos de conocimiento, con un enlace y aplicabilidad directos a situaciones cotidianas, con un papel activo del aprendiz, tanto en el plano mental como conductual y actitudinal. La investigación que ha empezando a comparar los aprendizajes formales, aquellos

(4) Ausubel distingue el aprendizaje significativo del aprendizaje por repetición. Ambos han sido erróneamente equiparados al aprendizaje por descubrimiento y al aprendizaje por recepción respectivamente. Sus consideraciones toman como referencia la circunstancia particular de la enseñanza en el aula y son trasladables, sin perder de vista la particular experiencia del visitante, al aprendizaje en el museo. En tal sentido, para Ausubel hay aprendizaje significativo... "si la tarea de aprendizaje puede relacionarse, de modo no arbitrario y sustancial (no al pie de la letra), con lo que el alumno ya sabe y si este adopta la actitud de aprendizaje correspondiente para hacerlo así. El aprendizaje por repetición, por otra parte, se da cuando la tarea de aprendizaje consta de puras asociaciones arbitrarias, como la de pares asociados, la caja de trucos, el laberinto o el aprendizaje de series; si el alumno carece de conocimientos previos relevantes y necesarios para hacer que la tarea de aprendizaje sea potencialmente significativa, y también (independientemente de la cantidad de significado potencial que la tarea tenga) si el alumno adopta la actitud simple de internalizarla de modo arbitrario y al pie de la letra (es decir, como una serie arbitraria de palabras." (Ausubel et al. 1983: 37) que se dan en el aula, y los aprendizajes informales, aquellos que se dan en contextos naturales, está empezando a mostrar que el aprendizaje informal no sólo es posible sino que es una herramienta muy potente para salvar algunas de las limitaciones más importantes del aprendizaje formal. En este nuevo escenario, los museos y exposiciones son un ámbito privilegiado para promover un acceso al conocimiento que, conservando el rigor necesario del mensaje científco, aporte una nueva mirada a los procesos del aprendizaje clásico. (Asensio y Pol 1996)

\section{La aproximación cualitativa y el análisis de discurso}

Para otorgar validez y coherencia teórico metodológica al estudio que proponemos es necesario recuperar el siguiente principio explicativo tomado de la semiótica: “... los fenómenos que constituyen el mundo no se nos dan desde sí mismos, sino que nosotros los identificamos adecuándolos a nuestras posibilidades de designación; ni contienen en sí mismos su razón de ser, sino que la proyectamos nosotros en función de las categorías disponibles en nuestra estructura conceptual; ni tampoco son vistos (ni comprendidos) tal como son, sino como nuestra modalidad de enunciación nos hace verlos (o comprenderlos) en el entorno perceptual correspondiente" (Magariños de Morentín 2008:66). ${ }^{5}$

(5) "En mi memoria asociativa, se actualizan una serie de atractores que me permiten establecer la afinidad entre las imágenes que veo y otras imágenes con las que estoy familiarizado, que percibí históricamente. En mi estructura conceptual se asocian conceptos semánticos, percepciones visuales y ( $\sin$ agotar componentes) experiencias kinésicas, que me permiten construir con las percepciones que pude asimilar en esta situación, un referente proyectado que interpreto (...) se lo que veo porque lo sitúo como objeto actual de otras representaciones (en cuanto representamenes o signos) de las que ya tengo el hábito de interpretar mi percepción. (...) lo percibido queda así caracterizado como objeto semiótico. (... ) utilizo lo que percibo para inferir algo que no estoy percibiendo, pero que resulta inferido por mi percepción. Cuando lo que veo ya no es (sólo) un objeto semiótico, sino que se constituye en signo de otra cosa a la que accedo como interpretación de la que percibo." (Magariños de Morentín 2008:79). 
Cuadro 2

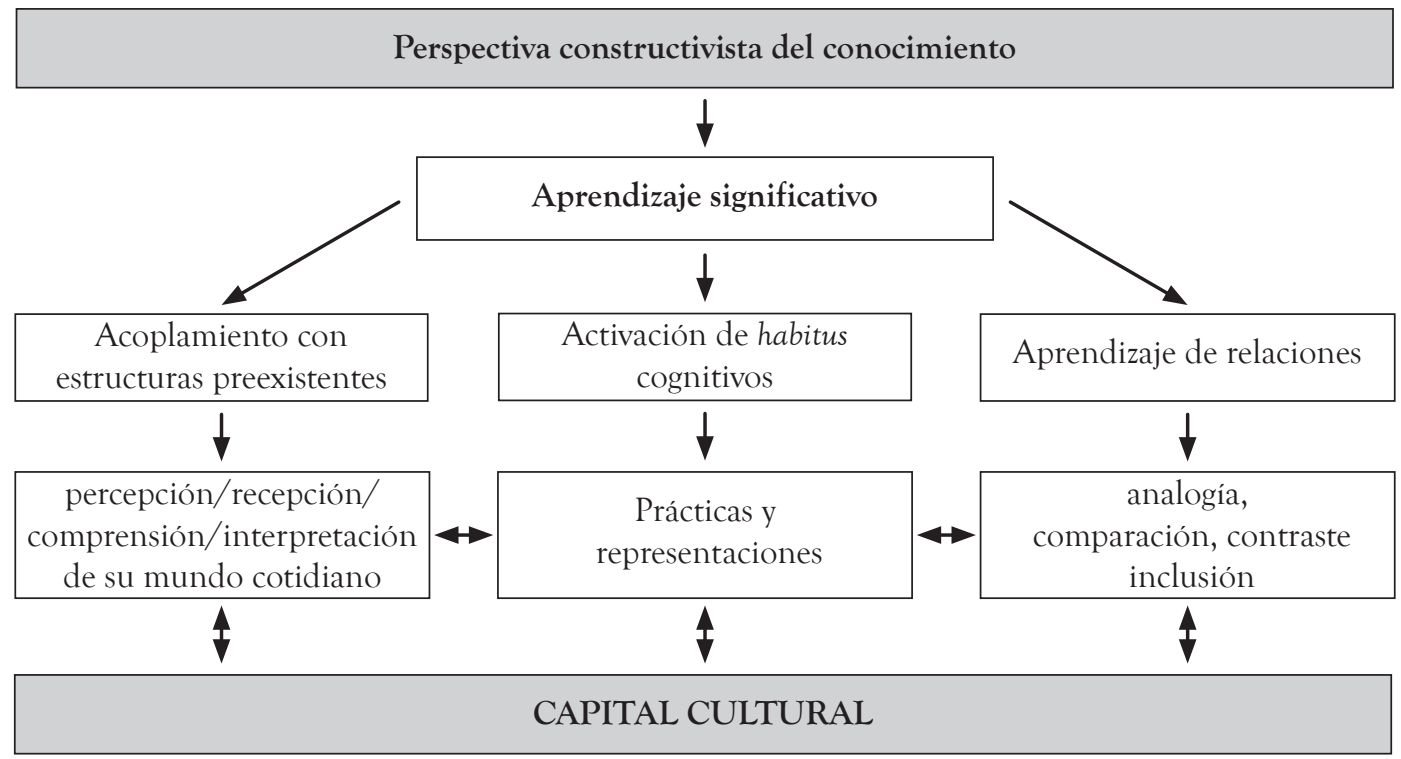

Este planteo semiótico implica que siempre que estemos ante el análisis de la significación será necesario identificar al sujeto/ intérprete inmerso en un contexto específico. Es decir que, la explicación de la significación tendrá que partir del modo en que el ser humano expresa cómo ese fenómeno ha entrado en su mundo de experiencia: lo expresa enunciándolo y entra en su mundo interpretando los enunciados (pan-semióticos) de su aprendizaje. El enunciado que él produce y los enunciados aprendidos constituye el corpus necesario para fundamentar cualquier investigación que pretenda explicar el significado atribuido a los fenómenos de su entorno. (Magariños de Morentín 2008)

Esta enunciación no se restringe al lenguaje hablado o escrito sino que incluye todas las posibilidades de semiosis sustituyentes (icónicas, simbólicas e indicales). El discurso es, entonces, una unidad compleja que abarca aspectos lingüísticos o simbólicos, icónicos e indiciales, de manera que la significación emerge en su articulación. A su vez, esta significación no es unívocamente interpretada por el visitante, no es nunca un espacio significante completo, acabado y definitivo, es el sustrato para configurar en el infinito juego de relaciones posibles, aquellas que, en concordancia con la estructura cognitiva del intérprete, resulta ser la expresión de los mundos semióticos posibles. ${ }^{6}$

En tal sentido, nuestro corpus de análisis lo constituye "lo dicho" o enunciado en el discurso de los visitantes. A partir de entrevistas semiestructuradas realizadas luego de la visita a la sala etnografía, se procedió al análisis de discurso y su posterior procesamiento según un programa computarizado para métodos cualitativos.

La ventaja de la elección de la aproximación cualitativa reside, entre otras razones, en la posibilidad que esta brinda de recomponer, desde la interacción abierta, la visión del mundo que construye el propio actor en una situación dada. Esta involucra técnicas de recolección de datos en la que las categorías descriptivas/interpretativas respecto de un referente concreto, para nosotros la sala de exhibición, surgen espontá-

(6) "A los fenómenos (....) los construimos, o sea, les conferimos existencia ontológica, en definitiva, los construimos ontológicamente, al nombrarlos y al enunciarlos o representarlos. (...) lo que producimos es la existencia del fenómeno para el conocimiento. O sea, sólo se conoce lo enunciable, teniendo en cuenta que lo enunciable no equivale, sólo, a lo verbalizable, sino que abarca toda forma de enunciación semiótica, sea ésta mediante íconos, índices o símbolos; de donde surge el texto pan-semiótico." (Magariños de Morentín 2008:75) 
neamente en el discurso de los entrevistados. (Reca y Martins 2007)

Por otro lado, la finalidad de los estudios cualitativos escapa a la búsqueda de regularidades traducidas en resultados estadísticos, por el contrario serán identificados patrones, tendencias, jerarquías y redes conceptuales. El hecho de que las categorías de análisis no estén preestablecidas y surjan durante la investigación permite captar la diversidad y dispersión del conjunto de significados que una comunidad particular construye en un momento dado, y su eficacia simbólica. A su vez, los datos no cuantificables pueden dar una visión holística y relacional de las múltiples aristas de la experiencia humana (Valles 1999). Nos interesa recuperar el significado social construido por el visitante a partir de la experiencia vivida en el recorrido de la sala, teniendo en cuenta su carga emotiva, estética y simbólica.

La semiótica simbólica y el análisis de discur$\mathrm{so}^{7}$ constituyen las herramientas teórico-metodológicas de análisis. El conjunto de procedimientos metodológicos incluye la aplicación de una serie de operaciones de normalización, segmentación, y diferenciación. Estas permiten identificar el conjunto de categorías utilizadas por el visitante en su interpretación sin incorporar, por parte del analista, elementos no enunciados, salvo aquellos que permiten dar unidad sintáctica a la oración concebida como unidad de análisis. ${ }^{8}$

(7) Se entiende por semiótica simbólica o semiótica de enunciados a aquella metodología de investigación destinada a explicar el significado de determinados fenómenos sociales cuando su representación/interpretación ha sido socialmente producida por textos simbólicos. Para nosotros, los discursos producidos por el visitante. El método propuesto consiste en un conjunto de operaciones concretas, sistematizadas y estandarizadas, siendo las entrevistas la materia prima del análisis. El discurso recuperado es concebido como "la representación de la configuración diferencial de dicho universo de valores y conceptos tal como aparece efectivamente enunciado en determinado corpus de discursos, es el objetivo específico al que aporta sus operaciones analíticas esta metodología semiótica" (Magariños de Morentín 2008:179)

(8) El análisis de discurso se diferencia del análisis de contenido al no admitir conocimiento a priori de ninguna clase, en cuanto al contenido semántico del lenguaje, sino que se propone explicar, respecto de cada término, de qué modo construye tal contenido o significación en función de su uso en el contexto material y positivo en el que aparece.
Esta metodología participa a su vez de una propuesta constructivista. El observador/analista construye su objeto de estudio a partir de estas atribuciones diferenciales. El análisis textual permitirá: - acceder al significado que adquiere el objeto de cual se habla, que no preexiste al discurso, el cual deja de ser lo que es en sí para que otra semiosis lo constituya; - establecer el significado del sujeto plural que no preexiste al discurso y que se construye en lo que resulta identificable en sus modalidades discursivas; - acceder al significado de los conceptos que se utilizan en los correspondientes textos y que no preexisten al discurso, pues su eficacia significativa proviene del contexto en el que aparecen; - este texto es entonces productor de interpretaciones dado que atribuye determinado significado a un ente, en nuestro caso las interconexiones entre los objetos, las imágenes, los textos, y los recursos expositivos y su configuración particular en una sala de exhibición para, finalmente dar cuenta de los distintos conjuntos temáticos aludidos durante el recorrido y su organización por inclusión y contraste-

\section{Las operaciones analíticas}

La operación se inicia en la identificación, a partir de una base sintáctica, las relaciones

Cuadro 3

CONTEXTO DE RE-PRESENTACIÓN

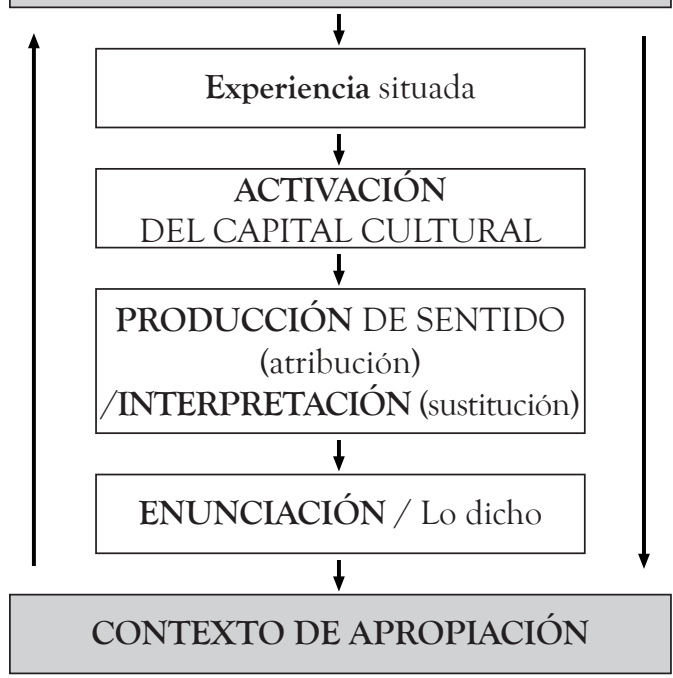


posibles entre las entidades físicas enunciadas, (de manera icónica, indicial o simbólica) en nuestro caso simbólica, las cuales no preexisten al discurso sino que éste le otorga carácter óptico. A partir de allí, mediante las operaciones de contextualización aparece el proceso de producción (atribución), las condiciones de interpretación (sustitución) y las posibilidades de transformación (superación). ${ }^{9}$

"La definición contextual es aquella mediante la cual se establece el sentido que adquiere un término cualquiera, presente en determinado segmento textual completo, en función del contexto al que dicho término aparece asociado en ese mismo segmento" (Magariños de Morentín 2008: 178).

A continuación se presenta un ejemplo de aplicación de las operaciones analíticas-

\section{Entrevista No 12}

MM: Trabajamos en el Museo y estamos haciendo una evaluación de público, ya que esta sala se inauguró recientemente, a ver qué les gustó más, si les gustó...

E: Me gustó mucho el Museo, todo en general. Muy sorprendido, hace tanto que no venía; pero lo veo muy interesante, muy remozado. Muy interesante ¿ De esta sala en especial?

\section{MM: Sí.}

E: Y si, es como un pedazo de la tierra donde nosotros vivimos, no? Me fascinaron las canoas, cómo vivían los antepasados, no? Más que, la situación de pensar desde los colonizadores, no? Yo toco la guitarra y me fui a ver la guitarra que habían traído de Europa. También vi el violonchelo, cómo lo habían cortado. Me

(9) Este procedimiento proporciona la explicación acerca de la semiosis disponibles en una sociedad. Las operaciones semióticas fundamentales son: "las de atribución (de un valor a una forma; identificación de un objeto semiótico por las relaciones sintácticas o contextuales), sustitución (o interacción entre una semiosis sustituyente y otra semiosisi sustiutuida); semantización de un objeto semiótico por parte de su contraste diferencial) y superación (de las contradicciones evidenciales por la aplicación de las precedentes semiosis sustituyete y sustituida, con la posible emergencia de un nuevo lenguaje; historicidad del objeto semiótico en función de la pragmática de su enunciación." (Magarños de Morentín 2008:157) pareció hermoso, muy interesante. La verdad que a mí me gustó mucho.

MM: Bueno, ite tomamos los datos?

\section{Normalización:}

(+a mi) Me gustó mucho el Museo (+a mi) (=me gustó) (=del museo) todo en general $(+y o)\{$ estoy\} Muy sorprendido (=del museo) $(+y o)$ hace tanto que no venía (=al museo) $(+\mathrm{yo}) \mathrm{veo}(=\mathrm{al}$ museo $)$ muy interesante $(+\mathrm{yo})$ $(=$ veo $)(=$ al museo) muy remozado (+para mi) (=esta sala) es como un pedazo de la tierra donde nosotros vivimos ( + a mi) (=de esta sala) Me fascinaron las canoas ( + a mi) (=de esta sala) (=me fascinaron) cómo vivían los antepasados (+a mi) (=de esta sala) (= me fascinó) la situación de pensar desde los colonizadores Yo toco la guitarra y me fui a ver (=en la sala) la guitarra que habían traído de Europa. (+yo) También ví (=en la sala) el violonchelo (+yo) ví (=del violonchelo) cómo lo habían cortado (+a mi) (=el violonchelo) Me pareció hermoso (+a mi) (=la sala) (=me pareció) muy interesante La verdad que a mí (=la sala) me gustó mucho

\section{Segmentación:}

1. (+a mi) Me gustó mucho el Museo

2. (+a mi) (=me gustó) (=del museo) todo en general

3. $(+y o)$ \{estoy\} Muy sorprendido (=del museo)

4. $(+y o)$ hace tanto que no venía $(=a l$ museo)

5. $(+y o)$ veo $(=a l$ museo $)$ muy interesante

6. $(+$ yo $)(=\mathrm{veo})(=\mathrm{al}$ museo) muy remozado

7. (+para mi) (=esta sala) es como un pedazo de la tierra donde nosotros vivimos

8. (+a mi) (=de esta sala) Me fascinaron las canoas

9. (+a mi) (=de esta sala) (=me fascinaron) cómo vivían los antepasados 10. (+a mi) (=de esta sala) (= me fascinó) la situación de pensar desde los colonizadores 11. Yo toco la guitarra y me fui a ver (=en la sala) la guitarra que habían traído de Europa 
12. (+yo) También ví (=en la sala) el violonchelo

13. (+yo) ví (=del violonchelo) cómo lo habían cortado

14. (+a mi) (=el violonchelo) Me pareció hermoso

15. (+a mi) (=la sala) (=me pareció) muy interesante

16. a mí (=la sala) me gustó mucho

\section{Definiciones contextuales:}

1. el museo es aquel que (+a mi) Me gustó mucho

2. (=el museo) es aquel que $(+\mathrm{a} \mathrm{mi})(=\mathrm{me}$ gustó) todo en general

3. (=el museo) es aquel del cual (+yo) \{estoy\} Muy sorprendido

4. (=el museo) es aquel al que (+yo) hace tanto que no venía

5. (=el museo) es aquel al que (+yo) veo muy interesante

6. (=el museo) es aquel al que (+yo) (=veo)

muy remozado

7. (=esta sala) es aquella que (+para mi) es como un pedazo de la tierra donde nosotros vivimos

8. (=la sala) es aquella de la que $(+\mathrm{a} \mathrm{mi}) \mathrm{Me}$ fascinaron las canoas

9. (=la sala) es aquella de la que ( + a mi) (=me fascinaron) cómo vivían los antepasados

10. (=la sala $\lcm{\text { es aquella de la que }}(+\mathrm{a} \mathrm{mi})(=$ me fascinó) la situación de pensar desde los colonizadores

11. (=la sala) es aquella en la que me fui a ver la guitarra que habían traído de Europa $\left\{{ }^{*}\right.$ porque $\}$ Yo toco la guitarra

12. (=la sala) es aquella en la que (+yo) También ví el violonchelo

13. (=el violonchelo) es aquel del que (+yo) ví cómo lo habían cortado

14. (=el violonchelo) es aquel que $(+\mathrm{a} \mathrm{mi})$ Me pareció hermoso

15. (=la sala) es aquella que $(+\mathrm{a} \mathrm{mi})(=\mathrm{me}$ pareció) muy interesante

16. (=la sala) es aquella que a mí me gustó mucho
El siguiente paso consiste en la agrupación de las definiciones según descriptores o nodos. Estos son conjuntos identificables como colectores de una mismo tipo de información. El procedimiento analítico incorpora el análisis comparativo de manera de agrupar las distintas definiciones contextuales por contraste o afinidad- A su vez, el análisis al interior de cada nodo o apartado permitirá nuevos niveles de contrastación/inclusión o tipo lógico. Este procedimiento también es denominado como método comparativo constante. ${ }^{10}$

Ejemplo del tratamiento el nodo conceptual: Tiempo

La alusión al tiempo está referenciada en el discurso de los visitantes a partir de distintos recursos expositivos. Conceptualmente se distinguen tres subnodos, aquel que toma como referencia el pasado, el que toma como referencia el presente y el que agrupa las definiciones contextuales donde el tiempo, a veces de forma implícita, está aludido como cambio o historia.

\section{Los niveles de análisis}

Durante el análisis los nodos fueron agrupados en tres niveles referenciales, de primer, segundo y tercer orden. El cuadro que sigue da cuenta de los nodos incluidos en cada uno de ellos.

Una vez definidos los nodos según sean de primer orden, segundo orden y tercer orden, se identifican el conjunto de enunciaciones que refieren a dicho nodo y que, por diferencia, darán lugar, según las relaciones posibles, a las redes contrastantes o mundo semióticos posibles para un corpus dado en determinado momento y lugar.

(10) La agrupación de definiciones contextuales y la configuración de nodos y sus niveles de inclusión fue informatizado a través de la aplicación del programa para datos cualitativos $\mathrm{N}$ Vivo, versión 1.3. El desarrollo de paquetes informáticos específicos para el análisis cualitativo exige al investigador la externalización de los procesos intelectuales que tienen lugar en las distintas fases del análisis. 


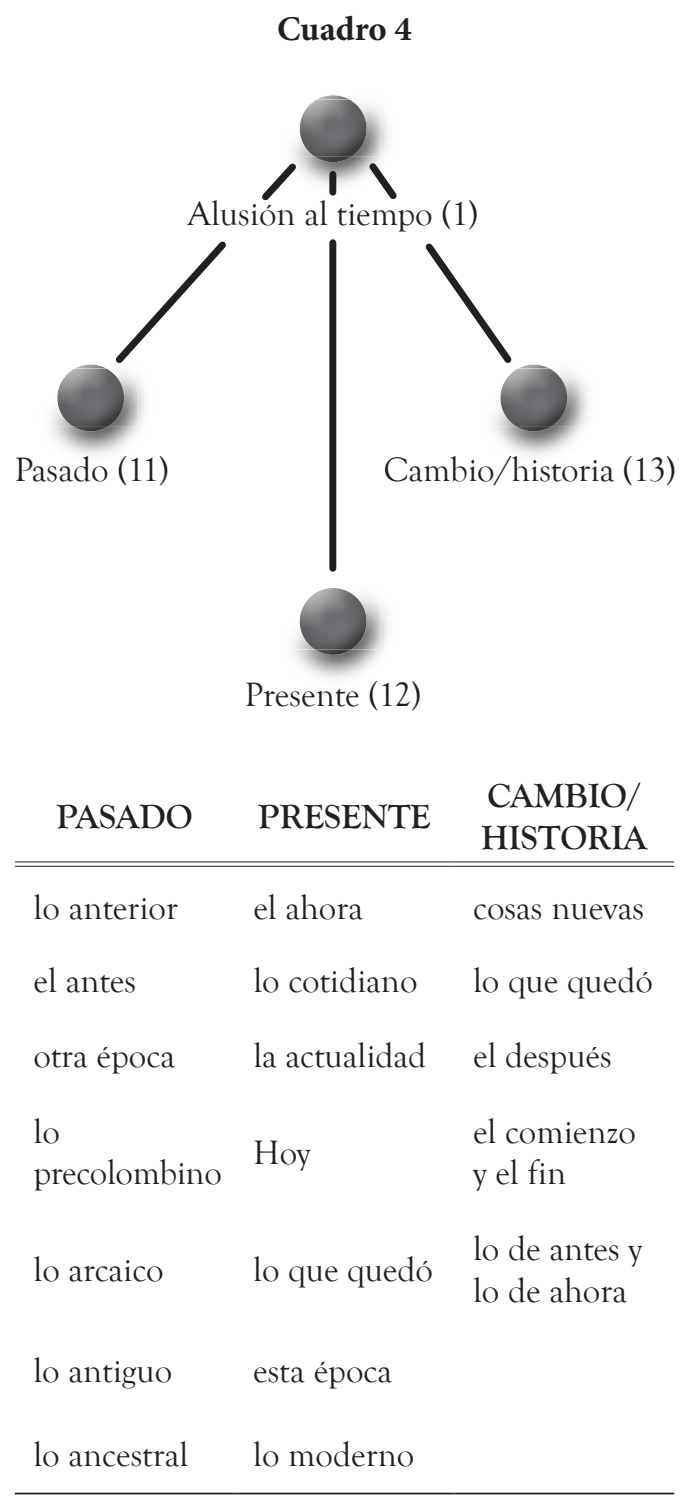

\section{Cuadro 5}

\begin{tabular}{|c|c|c|}
\hline $\begin{array}{l}\text { Referentes de } \\
\text { primer orden }\end{array}$ & $\begin{array}{l}\text { Referentes de } \\
\text { segundo orden }\end{array}$ & $\begin{array}{c}\text { Referentes de } \\
\text { tercer orden }\end{array}$ \\
\hline Objetos & Sector video & $\begin{array}{l}\text { Alusión al } \\
\text { tiempo }\end{array}$ \\
\hline Textos & $\begin{array}{l}\text { Sector final } \\
\text { o escenario }\end{array}$ & $\begin{array}{l}\text { Cultura / } \\
\text { identidad }\end{array}$ \\
\hline $\begin{array}{l}\text { generalidades } \\
\text { de la sala }\end{array}$ & $\begin{array}{l}\text { Sector } \\
\text { máscaras }\end{array}$ & Autoreferencia \\
\hline
\end{tabular}

Establecer las relaciones con los nodos y subnodos entre los distintos niveles permite generar las matrices de datos.

Ejemplo de matriz:

Alusión al tiempo/objetos-textos-generalidades de la sala

\section{Consideraciones finales}

Una vez identificados los apartados en los tres niveles de referencia, se cruzó la información estableciendo relaciones entre nodos de distinto orden, entre nodos y subnodos y con los datos del perfil sociodemográfico. A través de la interpretación de las matrices y sus resultados se configura una nueva instancia de interpretación en la cual se establecen correspondencias entre el contexto de apropiación (los discursos producidos por los visitantes) y el contexto de re-presentación (la sala como materia/texto

\section{Cuadro 6}

\begin{tabular}{|c|c|c|c|}
\hline \multicolumn{4}{|c|}{ Documentos } \\
\hline Matrix Nodes & (3) /Objetos & (7) / Textos & (8) /Generalidades de la Sala \\
\hline (1) /Alusi al tiempo & 1 & 3 & 10 \\
\hline \multicolumn{4}{|c|}{ Referencias } \\
\hline Matrix Nodes & (3) /Objetos & (7) / Textos & (8) /Generalidades de la Sala \\
\hline (1) /Alusi al tiempo & 1 & 3 & 13 \\
\hline
\end{tabular}


susceptible de ser interpretado). Además, se discriminan, para algunos casos, tendencias según edad, nivel de instrucción, entre otros.

El análisis permitió establecer correlaciones entre el contexto de re-presentación y el contexto de apropiación, recuperando así la referencialidad en la producción de sentido. A partir del análisis de discurso de "lo dicho" fue posible detectar los lugares/objetos/mensajes que aparecen con mayor frecuencia en los discursos de los visitantes e identificar la presencia de valores como la autenticidad, el tiempo presente, lo lúdico y la inclusión.

Por último, de este análisis resulta la evaluación de la eficacia comunicativa de la sala según las intenciones de los curadores y la visualización de los mundos semióticos posibles surgidos como consecuencia de la situación propuesta y, desde allí, afirmar que el desplazamiento conceptual pretendido por los curadores con la innovación de la sala encuentra anclaje en el contexto de re-presentación y una apropiación diferencial por parte del visitante.
Desde un punto de vista cognitivo y nutriéndose de las propuestas teórico metodológicas de la semiótica, este análisis permite conocer el conjunto de procedimientos por los cuales se ponen en juego categorías de pensamiento para arribar a la construcción de sentido, es decir, los conjuntos relacionales y asociaciones que se disparan al interior de la sala de exhibición, ancladas en los diversos objetos y recursos expositivos y desde el conjunto de ideas, nociones, conceptos y experiencias que cada visitante trae consigo, según sus hábitos cognitivos.

Así, los estudios de visitantes a museos, operan sobre la dimensión simbólica y cognitiva del patrimonio cultural y tienden a ocupar un rol fundamental en el campo de la gestión cultural y el análisis crítico. Los estudios de las diferentes modalidades de percepción/ interpretación tanto en las instancias de la recepción del público como de la producción por los expertos no son una área solo de interés académico, son una área crucial en la gestión del patrimonio cultural y la planificación de las nuevas funciones de los museos en el mundo contemporáneo. (Bialogorski y Cousillas 2004).

RECA, M.M. The study of museum audiences: the theoretical-methodological contribution of semiotics. R. Museu Arq. Etn., São Paulo, n. 21, p. 369-381, 2011.

Abstract: In recent years the need to investigate in greater depth the visit experience and inquire about the way in which visitors interpret the exhibition proposal, has become more relevant. Semiotics provides a set of theoretical/ empirical tools to apply a precise method that allows explaining the process of production, communication and transformation of meaning sciences. From a constructivist and cognitive viewpoint, traversed by the analysis of discourse as a methodological tool, the goal of this work is to evaluate the communication efficiency of a exhibition hall in the Museo de La Plata (UNLP). Our aim is to build a model by establishing relationships between the context of representation, the exhibition hall, and the context of appropriation, the discourses produced by visitors after the visit.

Keywords: Symbolic semiotics - Qualitative approach - Communication Museums - Audience studies. 


\section{Referencias bibliográficas}

ASENSIO, M.; POL, E.

1996 Cuando la mente va al museo: un enfoque cognitivo-receptivo de los estudios de público. Actas de las IX Jornadas Estatales DEAC- museos, Universidad Autónoma de Madrid: 83-134.

AUSUBEL, D.P.; NOVAK, J.; HANESIAN, H.

1983 Psicología Educativa. Un punto de vista cognoscitivo. México: Trillas.

ARIZPE, L.; NALDA, E.

2002 Cultura, patrimonio y turismo. In: Canclini, N. G. (Coord.) Iberoamérica 2002, Diagnóstico y propuestas para el desarrollo cultural. Buenos Aires. Santillana: 209-234.

BIALOGORSKI, M.; COUSILLAS, A.

2004 Métodos cualitativos y etnográficos en tareas de gestión: el Museo de Arte Popular José Hernández (GCBA) y el Banco de la Memoria en el Campo Artesanal. IV Jornadas de Etnografía y Métodos Cualitativos. Instituto de Desarrollo Económico y Social (IDES). Publicación en CD

BOURDIEU, P.

1996 Cosas Dichas. Barcelona: Gedisa.

CURY, M.X.

2005 Comunicação e pesquisa de recepção: uma perspectiva teórico-metodológica para os museus. Dossiê $4^{\circ}$ Congresso Mundial de Museus e Centros de Ciência. Museus e Ciências (História, Ciências, Saúde), 12: 365-380
MAGARIÑOS DE MORENTIN, J.Á.

2008 La semiótica de los bordes. Apuntes de metodología semiótica. Córdoba: Comunic-Arte.

\section{PEREZ SANTOS, M.E.}

2000 Estudio de visitantes en museos: metodología y aplicaciones. España: Trea.

PEIRCE, C.S.

1986 La Ciencia de la Semiótica. Buenos Aires: Nueva Visión.

POMIAN, K.

1990 Musée et patrimoine. In: Patrimoine en Folie. Edition de la Maison des sciences de l'homme. Ministére de la Culture et de la Communication. Collection Ethnologie de la France, París, Cahier 5: 177-198.

RECA, M.M.; MARTINS, M.E.

2007 Las exhibiciones y su público: una aproximación cuali-cuantitativa de la recepción de la sala etnografía del Museo de La Plata. Actas de las V Jornadas de Etnografía y Métodos Cualitativos. Instituto de Desarrollo Económico y Social (IDES), Buenos Aires, Argentina. Publicación en CD

VALLES, M.S.

1999 Técnicas cualitativas de investigación social. España: Editorial Síntesis.

ZUNZUNEGUI, S.

2003 Metamorfosis de la Mirada. Museo y Semiótica. Madrid: Ediciones Cátedra. 